http://dx.doi.org/10.1590/0102-4698121008

\title{
UM GAME PARA A PSICOLOGIA ESCOLAR: PROPOSIC̣ÕES TEÓRICO-METODOLÓGICAS PARA A CONSTRUC̣ÃO DE UM ARTEFATO LÚDICO-EDUCATIVO
}

\author{
Fernando Teles* \\ Larissa Medeiros Marinho dos Santos ${ }^{* *}$ \\ Cleci Maraschim***
}

RESUMO: Este artigo apresenta proposições teórico-metodológicas para o desenvolvimento e o uso de um jogo eletrônico educativo no âmbito da formação do psicólogo escolar, como objeto de uma investigação na área da Informática na Educação. Como mais um instrumento de aprendizagem, o jogo poderá mediar negociações com a Psicologia Escolar, estabelecendo uma porta de entrada para esse campo de estudos. Articulando as orientações da Teoria Ator-Rede, a Teoria da Enação e da Autopoiese, tecemos considerações sobre como a aprendizagem mediada por um game poderá dissolver dicotomias como aluno-professor, sujeito-objeto no ato de aprender e ensinar. No intuito de passar ao largo da prescrição didática no desenvolvimento de um software educativo, refletimos sobre a manutenção de uma posição simétrica para o ato de conhecer com base na proposta de uma epistemologia política para o ensino e a pesquisa.

Palavras-chave: Psicologia Escolar. Informática na Educação. Jogo educativo.

\footnotetext{
* Doutorando do Programa de Pós-Graduação em Informática na Educação da Universidade Federal do Rio Grande do Sul (UFRGS). E-mail nandotelles@yahoo.com

** Doutora em Psicologia pela Universidade de Brasília (UNB). Professora do Programa de Pós-Graduação em Psicologia da Universidade Federal de São João del Rei (UFSJ). E-mail: larissa@ufsj.edu.br

** Doutora em Educação pela Universidade Federal do Rio Grande do Sul. Professora no Departamento de Psicologia Social e Institucional da Universidade Federal do Rio Grande do Sul. E-mail: clecimar@orion.ufrgs.br
} 


\title{
AGAMEFORSCHOOLPSYCHOLOGY:THEORETICALAND METHODOLOGICALPROPOSITIONS FOR BUILDING A LUDIC EDUCATIONAL ARTIFACT
}

\begin{abstract}
This article posits theoretical and methodological propositions for the development and use of an educational computer game in the area of training educational psychologists and as an object of research in the field of Educational technology. As an additional learning tool, this game can be used to mediate agreements with School Psychology by establishing an opportunity to enter this field of study. By articulating the theoretical orientations from Actor-Network, Enaction and Autopoiesis, we consider how learning through a computer game will be able to help overcome traditional dichotomies in Education, such as student-professor, and subject-object. In order to avoid didactic directions for the development of an educational software, we reflect on the maintenance of a symmetrical position for the exercise of learning based on the proposal of a political epistemology focused on teaching and researching.
\end{abstract}

Keywords: Social Psychology. Technology Education. Educational Game.

\section{INTRODUÇÃO}

A escola é grande. Há nela três pavimentos repletos de corredores, salas de aula, banheiros e cômodos diversos. Alunos, professores e funcionários perambulam por estes espacos labirinticos e vez, ou outra se deparam comigo, como se tivessem algo a dizer. Foi numa ocasião dessas que encontrei a diretora. Ela pediu ajuda para lidar com os muitos problemas que enfrenta a escola. Os indices de reprovação e os registros de casos de violência são assustadores, e autoridades ameaçam fechar a escola caso esses indices não melhorem. Decidi então ir procurar pelos professores e funcionários e convidá-los para uma reunião. Eu tinha que encontrar um modo de obter um melhor entendimento do que estava acontecendo. Embora não soubesse ao certo no que isso daria, mantive o convite para a reunião. Alguns aceitaram de imediato, muitos o ignoraram e alguns até acabaram confirmando presença quando tomei certa distância e tentei posteriormente uma reaproximação. Tudo indica que preciso pensar e agir como um psicólogo. Eu vejo isso não apenas no modo como as pessoas interagem comigo, mas também nas histórias que contam. É chegado o momento da reunião. Todos aguardam por mim no auditório. É provável que eu tenha que realizar alguma intervenção e colher mais pistas sobre o modo de funcionamento da instituição. Será necessário pensar no melhor caminho a seguir. Se não conseguir tomar boas decisões, sentirei o peso das consequências: meu trabalho não terá feito qualquer diferença, e a escola continuará seu ciclo de problemas para o desespero da diretora, a insatisfação dos professores e a má formação dos alunos. Eu olho para a tela e vejo que a barra de progresso indica que estou apenas no início do jogo. Há muito o que fazer e já começo a me lembrar dos artigos que li no curso da disciplina de Psicologia Escolar no início do semestre. Salvo o jogo e desligo meu computador. Recomeço amanhã. 
O fictício relato acima nos conta como poderia ser a experiência inicial de um jogador do jogo educativo School Psychology Challenge (SPC), que desenvolvemos como um objeto de aprendizagem para a formação do psicólogo escolar em uma pesquisa de doutorado realizada no Programa de Pós-Graduação em Informática na Educação da Universidade Federal do Rio Grande do Sul e em parceria com o Departamento de Psicologia da Universidade Federal de São João del-Rei. A fim de aguçar a imaginação e o interesse de nossos leitores, só ao fim da narrativa aludimos ao fato de que o personagem narrador descrevia seus passos em uma escola meramente imaginada e visualizada com o auxílio de um computador pessoal. Por outro lado, em meio à aparente simplicidade dessa história, encontra-se nosso jogador diante de reflexões, surpresas e ideias que arrastam uma rede inteira de problemas que se conectam e interessam à Psicologia Escolar, às instituições de ensino de todos os níveis, aos game designers e às recentes controvérsias produzidas em meio ao campo de estudos que propõe o uso dos games na educação (CLARK, 2012; GEE, 2002; 2003; 2005; 2008a; 2008b; GEE E HAYES, 2012, MICHAEL E CHEN, 2006; SATWICZ E STEVENS, 2007; 2008; STEVENS, SATWICZ, \& MCCARTHY, 2008; SHAFFER, 2012; SHAFFER et al., 2005; SHAFFER E GEE, 2005; 2006; SQUIRE E JAN, 2007; STEINKUEHLER, 2006a; 2006b; STEINKUEHLER, SQUIRE, \& BARAB, 2012). Nos referimos ao fato de que os games hoje ganham o noticiário e as páginas dos periódicos científicos que os descrevem como instrumentos de pesquisa (COOPER et al., 2010), artefatos de auxílio a tratamentos de saúde (HOFFMAN, PATTERSON, \& CARROUGHER, 2000; KATO, 2010), mercadorias de uma indústria bilionária (ABRAGAMES, 2004; ENTERTAINMENT SOFTWARE ASSOCIATION, 2009; GARTNER, 2011), fonte de alienação e violência (ALVES, 2005) e o pivô de transformações culturais que implicam a proposta de um novo tipo de educação em crítica ao ensino tradicional (GEE, 2002; 2003).

Se de um lado os acadêmicos e a opinião pública ainda divergem quanto ao valor formativo dos games (GEE, 2003), resolvemos tomar partido nessas discussões com a mão na massa quando propusemos a construção de um jogo educativo para a formação do psicólogo escolar. Como qualquer obra artística, literária ou científica, preferimos considerá-lo como um software em constante fase de aprimoramento, sem qualquer pretensão de atingir um ponto final, ou um estado ótimo e estável sobre suas condições de ensino e aprendizagem de Psicologia Escolar. Com isso, convidamos 
o leitor a pensar conosco acerca do potencial educativo dos games enquanto discorremos sobres as articulações teórico-metodológicas que têm sustentado a construção e o uso do SPC.

Em diálogo com a Teoria Ator-Rede (TAR) desenvolvida a partir dos Estudos da Ciência e Tecnologia (LAW E CALLON, 1988; 1992; CALLON, 1987; LATOUR, 1988; 1996; LATOUR E WOOLGAR, 1997; LAW, 1987; 2002) e com as Teorias da Enação (VARELA, THOMPSON, \& ROSCH, 1991; VARELA, 1997) e da Autopoiese (MATURANA E VARELA, 1995; 1997), seguimos as orientações de Bruno Latour (1991; 1996; 2000a; 2001a; 2001b; 2005; 2007) no que diz respeito à noção de rede para a compreensão do fenômeno da aprendizagem em meio aos coletivos por onde circulam conhecimentos e técnicas. Quando situamos a aprendizagem como produto híbrido de associações em rede, a cognição deixa de ser um esforço epistemológico abstrato no qual o conhecer dependeria da díade sujeito-objeto e se distribui em práticas de mediação na mobilização de discursos, objetos e coletivos. Aprender Psicologia Escolar, por conseguinte, é mais abrangente do que acumular informações transmitidas, mas decorre de práticas engajadas em um campo onde interesses e regras são definidos a cada caso.

No intuito de superar as limitações das práticas pedagógicas lineares, nas quais a resolução dos problemas passa pela formulação de uma resposta correta, argumentamos que a exploração de um ambiente virtual aproxima o estudante das práticas de um determinado campo de conhecimento. A vantagem reside em introduzir o jogador em meio a desafios de um campo em ação no enfrentamento de questões que quase nunca ganham as páginas dos livros e que necessitam aguardar o estágio para serem enfrentadas: o tempo entre a imersão na experiência e a sua análise, as condições do ambiente escolar, a necessidade de repensar os objetivos das intervenções diante do inesperado, bem como a redefinição do próprio problema a ser analisado.

A virtude de um game educativo está em disponibilizar recursos com os quais o conhecimento pode ser mobilizado, fabricado e incorporado como atividade concreta e situada. Como objeto de aprendizagem, o jogo é uma das muitas formas de negociação com o coletivo que não se limita ao tipo de experiência que descrevemos na pequena história acima. Neste estudo, ele concretiza nosso interesse em utilizá-lo como uma porta de entrada para o campo da Psicologia Escolar. Trata-se de empregálo como dispositivo para auxiliar o estudante a habitar o campo 
de controvérsias teórico-metodológicas da referida disciplina. Desse modo, ele resume os objetivos desta pesquisa em propiciar a formação de conceitos a partir da ação e como instrumento de experimentação e investigação diante de um domínio de problemas.

Com base nessas considerações, refletimos sobre como uma educação baseada em games e a experiência incorporada ao jogar podem contribuir para o exercício de uma epistemologia política (LATOUR, 2007) na proposição de métodos de pesquisa e no uso do game como um objeto de aprendizagem.

\section{REDE, COGNICฺ̃̃O E APRENDIZAGEM}

Bruno Latour é frequentemente citado pelos proponentes de uma educação baseada em games, em referência a propostas pedagógicas mais imersivas, orientadas pela prática e mediadas por ferramentas e recursos técnicos (GEE, 2005; SQUIRE E JAN, 2007). Com base no trabalho de Latour, há autores que defendem revisões teóricas mais profundas sobre o que significa aprender em meio à multiplicidade da rede de objetos técnicos entre os quais os games constituem um dos nós (GEE, 2002; 2003; 2005; 2008a; 2008b; SATWICZ E STEVENS, 2008; SATWICZ E STEVENS E McCARTHY, 2008; SHAFFER, 2012).

Em seus textos, o autor examina a ciência sob uma perspectiva antropológica, vasculhando as redes que participam da fabricação de fatos científicos. Para a TAR, não há distinção essencial entre sociedade, ciência e tecnologia e seus atores são simetricamente analisados, não havendo hierarquias ou essências entre humanos e não humanos, o erro ou a verdade. O que interessa é a particularidade das ações que realizam na manutenção de suas conexões. A abordagem antropológica da TAR consiste em investigar a ciência como faria um antropólogo em uma tribo exótica. No entanto, o que é tomado de empréstimo da antropologia não é uma valorização do sentido de antropo (homem) como o princípio norteador dos estudos antropológicos, mas o estranhamento diante de um coletivo, como é comum nessa disciplina.

Segundo Latour (2005), assim como a ciência, qualquer associação humana é altamente mediada por objetos. Dada a ideia de que os coletivos são constituídos por híbridos de sociedade e tecnologia, o autor prefere defini-los pelo termo coletivos sociotécnicos. Os fatos científicos, relacionais assim como os artefatos técnicos, são produtos de muitos desvios, bifurcações que arrastam coletivos heterogêneos 
como aliados para sua constituição e, por isso, traem em muito as definições oferecidas pela epistemologia clássica do que vem a ser o conhecer. Dessa forma, não se trata de pensar como é possível o conhecimento de um mundo dado previamente por uma mente que o investiga, mas sim verificar que coletivo sociotécnico foi agenciado para que tal tipo de conhecimento se tornasse viável e validado.

Com um enquadre metodológico mutável, a TAR não recorre às tradicionais categorias como social, indivíduo, mente, entre outros, para explicar fenômenos. Nem tampouco diferencia ciência de sociedade. Compreendendo qualquer fenômeno como decorrente do encontro entre entidades heterogêneas em ação, o termo social é substituído por associação para descrever o modo como efeitos se deslocam em rede. Dessa forma, a TAR se dispõe como um método para acompanhar o movimento de associações de atores, procurando entender como estes interagem e trocam propriedades na constituição de configurações mais ou menos estáveis (LATOUR, 2005).

O trabalho de pesquisa possui um caráter performático, já que o próprio pesquisador é também um ator que produz efeitos e deixa rastros por onde passa, se valendo da idiossincrasia de seus desvios, negociações, resistências e estratégias (LATOUR, 2005). Porém, o fato científico nunca é o produto do trabalho de um único ator. Um fato ou um objeto se desloca na rede, é transformado e está sempre em vias de estabilização ou fragmentação. Nesse movimento, postulados, conceitos ou instrumentos só adquirem valor científico quando são capazes de mobilizar o interesse de humanos e não humanos em uma rede, ganhando em objetividade e durabilidade na medida em que conquistam aliados, como se se preparassem para uma guerra. Quanto mais atores conquistados, mais objetiva ou estável se tornará uma determinada proposição ou objeto diante de argumentos contrários (LATOUR, 2000a).

O mesmo ocorreria com as máquinas e os softwares. No enquadre teórico-prático da TAR, a própria tecnologia consiste em estabilidades temporárias de associações que, quando conectada a outras redes, engaja-se no fazer sempre imprevisto de outros atores, participando do surgimento de híbridos que respondem pelo operar em conjunto de discursos, objetos, pessoas, instituições etc. Para este projeto, esperamos arregimentar quantos atores forem necessários para ultimar a concepção de um jogo como objeto técnico para a construção de conhecimento sobre a Psicologia Escolar.

Sob a luz da TAR, interessa-nos investigar como o objeto técnico participa da invenção do conhecer e como este retroage na 
produção de efeitos sobre o primeiro. Como nenhum desses dois polos é tomado como ponto de partida, a aprendizagem é definida como o trabalho imprevisível da errância, como as transformações que surgem a partir de performances que fabricam sujeito e objeto (MORAES, 1997). Logo, conhecer não é representar a realidade, mas sim participar da construção de um mundo comum, afetar e deixar-se afetar. As perguntas mais interessantes são aquelas que indagam acerca do que acontece no meio, nas muitas negociações que oportunizam vínculos nos agenciamentos de humanos e não humanos.

Para as Ciências Sociais, o método da TAR sugere que os coletivos devem ser estudados em seus movimentos de associação, em contraste com a sociologia tradicional que toma a sociedade como uma instância explicativa para os ditos fenômenos sociais. Trata-se de estudar a formação de vínculos entre atores heterogêneos e não de estabelecer, a priori, a que tipo de forças esses mesmos atores estão submetidos. A sociedade, portanto, é um ponto de chegada e não de partida para a compreensão dos coletivos (LATOUR, 2005). Um objeto técnico como um jogo pode ser visto como uma estabilidade temporária de muitas associações, negociações, discursos e outros trabalhos que possibilitaram seu surgimento.

Ao incluir entidades não humanas em seu enquadre de análise, a TAR procura capturar os vínculos que constituem e hibridizam os atores que participam das redes investigadas. Nos vínculos estabelecidos entre humanos e não humanos verifica-se o que e como um faz o outro fazer. Se os vínculos são bons, há mais recursos e ações à disposição dos envolvidos. Os atores mais livres são aqueles que, com muitas conexões, possuem mais condições de trafegabilidade pelas redes às quais aprendem a se conectar. $\mathrm{O}$ contrário indica o mal vinculado, o empobrecido que, por possuir poucas conexões se encontra isolado e menos capaz de se reinventar e estabelecer novos vínculos (LATOUR, 2000b; 2005; TSALLIS et al, 2006). No caso do jogo eletrônico, trata-se de um tipo de objeto altamente conectado a histórias, práticas, polêmicas, interesses de mercado, entre outros, que contribuem para a crescente vascularização da rede que o sustenta. Esse fato já se evidencia na permeabilidade dos games com outros campos do saber que, além de multiplicar suas chances de sobrevivência como tecnologia, têm viabilizado propostas no âmbito da educação como a que apresentamos neste texto. Aprender com os games pode ser uma oportunidade de compreender o funcionamento de sistemas complexos, resolver problemas, exercitar habilidades de uma profissão, engajar-se em interações cooperativas, acompanhar o 
enredo de uma história etc. Tais possibilidades, que não se esgotam nesta breve lista, ampliam a gama de estratégias didáticas para o ensino e abrem novos caminhos para a Educação (GEE, 2002; 2003).

Contudo, estudar a aprendizagem com base na TAR requer que aceitemos seu caráter de incerteza para que possamos acompanhar a construção daquilo que assumimos como racional ou inteligível em nossos modos de conhecer. Só assim podemos passar ao largo das dicotomias para compreendermos como sujeito e objeto são fabricados, sem termos que tomá-los como fundamentos gerais explicativos sobre a cognição (MORAES, 1998). É por duvidarmos de tais fundamentos que preferimos olhar para o meio, o território das práticas onde o real é inventado e a emergência do conhecimento não padroniza suas condições de possibilidade (KASTRUP, 1999/2007). A cognição que examinamos na experiência do jogar é aquela posta em meio a um coletivo, ao mesmo tempo simulado na temática da Psicologia Escolar e concreto nos agenciamentos teóricos e materiais que o coloca em movimento.

Essas considerações encontram ressonâncias na Teoria da Enação de Francisco Varela e colaboradores (VARELA, 1997; VARELA et al., 1991) em relação às Ciências Cognitivas que se ergueram a partir da separação entre sujeito cognoscente e realidade objetiva. Conforme os autores, as transformações pelas quais passaram as ciências e as técnicas deflagraram práticas sociais geradoras de um conhecimento específico. Questionamentos advindos dos interesses do programa de investigação da Inteligência Artificial teriam contribuído para difundir a noção de que a cognição funciona como uma máquina de processamento de símbolos. Consequentemente, a experiência humana teria deixado de ser espontânea quando as ciências tomaram partido sobre sua definição.

Como exemplo, os autores atribuem à corrente cognitivista a responsabilidade pela difusão de modelos da mente baseados na metáfora do computador digital. A partir desses modelos, uma computação é uma operação simbólica e a cognição é compreendida como representação mental do mundo (VARELA et al., 1991). As consequências desse pensamento para as práticas coletivas mais amplas são inúmeras. Poderíamos citar as próprias políticas educativas ainda vigentes que propagam a ideia de que o conhecimento é decorrente da representação do mundo.

As reflexões de Varela (1997) aproximam-se ainda mais da TAR na sugestão de que a difusão dos modelos de representação da realidade exclui o senso comum da definição de cognição. Com isso, o autor indica a idealização de um mundo pré-determinado 
praticado pelo cognitivismo, que apenas ingenuamente se purifica das complexas redes envolvidas na concepção dos estudos sobre a mente. Disso decorre a simplificação do que vem a ser o conhecimento, obscurecendo os muitos desvios, articulações e negociações que participam da produção da cognição. Como resultado, as investigações tendem a priorizar a resolução de problemas discretos, visando à redundância da correspondência mente-mundo. Desse modo, um objeto de aprendizagem que coloca o estudante em um sistema complexo que não representa, mas que constitui uma realidade simulada, pode trazer experiências de um modo de aprender mais processual, implicado e contingente.

Para a Teoria da Enação, no entanto, o mundo não é representado, mas trazido à mão pela estrutura do ser vivo e pelas distinções que este é capaz de realizar em seu meio. A cognição é descrita como a enação de um mundo e de uma mente a partir de um histórico de ações realizadas por um ser no mundo. As questões que surgem em nossa vida não são pré-definidas, mas enatuadas ${ }^{1}$, pois participamos de seu surgimento. Os critérios para sua emergência são definidos a cada momento, no fluxo da errância dos acontecimentos. Logo, se nosso destino comum é o devir errático das redes nas quais habitamos, não faz sentido falarmos em representação de algo dado, pré-definido (VARELA et al, 1991), pois o real, assim como pensa Latour (2007), é sempre uma construção.

Essas reflexões nos remetem à Teoria da Autopoiese, proposta por Francisco Varela em coautoria com Humberto Maturana (1997) e cuja ontologia teria fornecido as bases teóricas da Enação. Movidos pelo interesse de investigar as origens dos seres vivos, os autores propuseram o conceito de autopoiese para designar e distinguir os processos que permitem o surgimento e a manutenção da vida. Em contraposição às teses evolucionistas, os autores alegam que a existência de um ser vivo não teria sentido fora de si mesmo. Ela seria, de fato, o resultado de uma dinâmica sem propósitos.

$O$ vivo teria surgido na errância, no encontro acidental de componentes que encontraram estabilidade em determinado momento de sua história de interações, como os fenômenos em rede relatados por Latour (2005). Operando como um sistema fechado, um organismo continua vivo enquanto seus componentes forem capazes de produzir os próprios componentes que os produziram. Para isso, se dispõe ao devir criativo, realizando acoplamentos estruturais com o meio na realização conjunta de espaços de existência (MATURANA E VARELA, 1997). 
Entre meio e ser vivo não há troca de informação, só modulações que deflagram modificações na estrutura do indivíduo, sem prejuízo para sua integridade operacional. A recorrência dessas interações pode instituir novas regras, instaurar pautas inéditas de ação coletiva (MARASCHIN E AXT, 2005) e tornar estáveis certos modos de acoplamentos estruturais. É por isso que parece razoável a consideração de que nossa convivência com a multiplicidade de tecnologias da informação tem criado novos domínios de ação e produção de conhecimento.

Longe dos binarismos ontológicos modernos e em posição crítica às neurociências, a Teoria da Autopoiese não limita suas explicações sobre os fenômenos cognitivos às estruturas neurológicas. Em vez disso, qualquer estrutura biológica só será associada à cognição a partir da conduta ou do histórico de interações do ser em um ambiente. Por sua vez, as condutas participam das mudanças das estruturas cerebrais. Portanto, o ser troca propriedades com seu ambiente. Essas considerações recaem sobre a importância de que a experiência do ser deveria ser levada em conta pelas explicações científicas.

Em Latour e Varela, a aprendizagem é o destino do corpo. $\mathrm{Na}$ definição de Latour (2007), o próprio corpo é um processo de aprendizagem. No projeto de estudo dos dois autores (LATOUR, 2007; VARELA, 1997; VARELA et al., 1991), esse enunciado aparece como aquilo que designa a corporificação da mente que, livre da camada ontológica da representação, realiza acoplamentos diretamente com o mundo. Quando aprendemos, nos articulamos com algo, explorando seus efeitos em nós enquanto experimentamos suas possibilidades e resistências. Em rede, essa aprendizagem não é determinada pela força de uma entidade sobre outra, mas é o que se situa no meio, no território das práticas onde nosso fazer nos hibridiza e nos permite habitar outros domínios.

Apresentar o problema dessa forma também equivale a considerar que as capacidades sensoriomotoras do corpo, performadas em determinados contextos, adquirem significados particulares porque são socializadas e descritas com o auxílio das entidades com as quais estabelecemos relações recorrentes (VARELA et al., 1991). Nesse sentido, o corpo também é enatuado. O mundo não nos instrui quando aprendemos, mas tomamos partido na definição do que deve ser problematizado a cada instante. Por isso, mesmo diante de instruções simbólicas sobre como usar um objeto técnico, por exemplo, nossa aprendizagem ainda corre riscos. 
Ler descrições ou ouvir palestras podem ser formas de interessar, mas o aprender também envolve negociar resistências e proximidades a fim de que corpo e objeto se articulem e operem como uma nova unidade. Quando jogamos um videogame, também produzimos conhecimento incorporado (GEE, 2003).

O surgimento de um domínio cognitivo, portanto, está subordinado à efetividade da ação que um organismo é capaz de performar em seu ambiente (VARELA et al, 1991). Essa reflexão parece alinhada com as propostas de Bruno Latour (2007) para a realização de uma teoria calcada em uma ontologia em rede. Sob uma perspectiva simétrica, conforme o autor, devemos compreender o sujeito como resultado das trocas de propriedades que realiza com o mundo enquanto um corpo concreto. O corpo, nesse sentido, seria uma interface que vai ficando mais descritível enquanto aprende a ser afetado por muitos mais elementos. Essa posição, além de suscitar o distanciamento em relação à dicotomia sujeito-objeto, comunga com o projeto de uma cognição incorporada que não toma o mundo como algo a ser representado, mas performado ou enatuado.

Ao fazer jus à simetria, o pesquisador interessado em compreender a cognição dos corpos que investiga deve se valer de métodos que ponham em risco seus próprios procedimentos, deixando um espaço comum de coautoria das explicações científicas. Nesse sentido, o real é sinônimo de construção e não de representação, uma vez que o conhecer depende das transformações pelas quais passa o corpo que se deixa afetar (LATOUR, 2007).

Aprender não é processar símbolos, mas experimentar o mundo e articular-se com ele. Essas reflexões dão base ao nosso interesse de produzir um jogo educativo para a formação do psicólogo escolar. Orientados por essa concepção de aprendizagem, acreditamos que os games permitem realizá-la na medida em que oportunizam experiências incorporadas articuladas com as propriedades do que se deseja aprender.

Assim como qualquer objeto técnico, os games possuem agência, nos fazem realizar coisas que podem, em grande medida, ultrapassar seu programa de ação original. Enquanto afetamos e por eles nos deixamos afetar, criamos outras redes, performamos novos problemas e nos constituímos como indivíduos, contribuindo para a perpetuação das redes às quais estamos ligados (LATOUR, 2000b; 2005; TSALLIS et al., 2006).

Atentos para os postulados da Teoria da Enação (VARELA et al., 1991; VARELA, 1997), apostamos na ideia de que os games 
podem servir ao exercício da cognição inventiva se estes, em vez de apenas informar, se dispuserem como um recurso para a produção de distinções sobre um campo de estudos. Com base na TAR, esperamos conceber um dispositivo capaz de performar versões da Psicologia Escolar. Com isso, desejamos manter nosso respeito à diversidade da rede de atores dessa disciplina e das salas de aula em que o jogo será colocado à prova.

No trabalho de Satwicz e Stevens (2007), que também faz referência às considerações de Latour, os autores realizam incursões etnográficas a sessões de partidas de videogames em ambientes domésticos. Com isso, fornecem ilustrações de como as interações cooperativas com os games produzem aprendizagem. Conforme os referidos autores, os games permitem a criação de diferentes configurações coletivas. Em um exemplo em que dois jovens se ajudam na tarefa de vencer os desafios da fase de um jogo, os autores pontuam o fato de que a presença do colaborador, o compartilhamento de dúvidas, experiências e o revezamento na posse do controle etc. produzem constantes autoavaliações que culminam sempre em níveis diferenciados de reorganização. Satwicz e Stevens (2007) acrescentam que reorganizar-se no decorrer da aprendizagem é possível quando há reservas de recursos materiais e/ou humanos sobre as quais apoiar memórias e outros recursos. Já que os games possibilitam a construção dessas reservas em diferentes arranjos técnicos, os mesmos não exigem respostas imediatas para a resolução de problemas. Há um espaço de ensaio em que o game como objeto técnico facilita a emergência de associações e faz criar estabilidades (TELES, 2011; TELES, QUEIROZ E MELO, \& NEPOMUCENO, 2012). O jogador não precisa de conhecimento prévio para jogar, mas apenas estar disposto a levar adiante a aprendizagem para propor soluções, resolver enigmas.

Essa característica nos lembra que, para a TAR, a tecnologia é o que torna a sociedade durável. Por existirem técnicas, não estamos sempre à mercê do acaso de nossas interações quando precisamos negociar novas ações com o coletivo, mas contamos com a força do passado, impingida nos objetos por outros atores. A técnica é, portanto, uma forma de socializar nossos interesses com os não humanos para agirmos à distância, no tempo e no espaço. Quem quer que se encontre diante de um aparato técnico estará, na verdade, diante de muitas relações sociais (LATOUR, 1994b). Com essa sugestão, Latour $(1991 ; 1994 b)$ indica que a técnica pode ser convocada a agir quando desejamos reforçar o cumprimento de 
programas de ação. Conforme Latour (1991), afirmações imperativas podem ser deslocadas com a introdução de objetos técnicos que assegurem o cumprimento de ações de acordo com novos interesses. Delegamos às técnicas preceitos morais ou jurídicos quando instalamos quebra-molas nas vias públicas, por exemplo (MORAES, 1997). No caso desta pesquisa, procuramos desdobrar, em um game, a força de algumas proposições sobre o ensino da Psicologia Escolar e dos interessados por essa disciplina. O game é o que nos permite dobrar o tempo, fazendo agir no aqui e agora aqueles atores que colaboraram, de alguma forma, para o que vem a ser um determinado campo de estudos. Com isso, gostaríamos de privilegiar a prática de habilidades que acreditamos estarem próximas àquelas requeridas pelo trabalho do psicólogo escolar.

De acordo com o Conselho Federal de Psicologia (2000), o profissional desse campo atua na produção de pesquisa e intervenção em todas as dimensões da atividade educativa. Seu trabalho é realizado em conjunto com professores e outros profissionais da educação, elaborando, implementando, avaliando e reformulando currículos e políticas pedagógicas. Para os objetivos desta pesquisa, procuramos distribuir e demarcar, em um game, as habilidades e tarefas do psicólogo em oportunidades para investigar histórias, observar e comparar versões de fenômenos e identificar as consequências de suas ações.

\section{REUNINDO PROGRAMAS DE AC̣ÃO: A CONSTRUC̣ÃO DO JOGO}

Latour (1991) nos fala que embora não haja garantias de que um plano de ação será executado de acordo com determinadas expectativas, o emprego de uma ou mais técnicas visa enfatizar uma afirmação original com a introdução de quantas ênfases forem necessárias para fazer frente às resistências apresentadas pelos actantes humanos que precisam ser cooptados. No trabalho das associações, os efeitos não podem ser previstos, pois suas causas apenas dispõem a ocasião para seu surgimento (LATOUR, 2005). $\mathrm{O}$ autor usa o termo mediador para se referir ao actante cuja ação está sempre produzindo algo diferente do que dele se esperava ao interagir com outras entidades. Um mediador, portanto, não seria o mesmo que um intermediador, que apenas transporta uma ação sem modificá-la, servindo apenas de meio. Essas considerações nos remetem aos significados postulados por Latour (2001a, p. 205) para o conceito de mediação técnica, subdividido entre os conceitos de 
interferência, composição, obscurecimento reversível e delegação, sobre os quais trataremos a seguir em articulação com nosso dispositivo técnico.

\section{INTERFERÊNCIA}

Conforme Latour (2001a), quando utilizamos as técnicas, compartilhamos com elas a responsabilidade das consequências de seus programas de ação. Outro ator é forjado quando o programa de ação de um objeto se junta ao nosso no agir. O mesmo vale para este estudo ao acolhermos as interferências disponíveis no emaranhado tecnológico utilizado na fabricação de um game. Recorremos a uma série de desvios que advêm da escolha do traçado dos personagens, da narrativa, da escolha da trilha sonora, das animações, da forma de controle dos avatares, entre outros. Em conjunto ou individualmente, esses detalhes colaboram para moldar a experiência do jogador e proporcionar oportunidades de ação sempre imprevisíveis.

\section{COMPOSIC̣̃̃O}

Por composição, Latour (2001a) descreve o alinhamento de diferentes subprogramas de ação para a realização de um programa principal. Isso é possível através de uma sucessão de desvios para cumprir os objetivos de cada um dos subprogramas agregados. Assim o fazemos para a construção de algo tão complexo como um jogo eletrônico. Reunimos concepções teóricas, softwares, pessoas e os combinamos com nossos próprios interesses em produzir um dispositivo de aprendizagem. Nas mãos dos usuários finais, o resultado poderá ser ainda muito imprevisível.

\section{OBSCURECIMENTO REVERSÍVEL}

O complexo emaranhado de programas de ação reunidos para a estabilização de um objeto técnico tende a ficar obscurecido quando este é finalizado. Isso ocorre quando o resultado final do programa de ação principal torna-se básico diante dos demais atores da rede à qual se conecta. Enquanto funcionar sem problemas o objeto permanecerá invisível, até que uma pane ocorra e isso mobilize outros atores para recompor suas partes e recuperar seu funcionamento. Nessa ocasião, uma caixa-preta é aberta e todos os passos que levaram à sua construção são refeitos, o que poderá reverter o obscurecimento e revelar os atores que participaram de sua composição. No caso de nosso jogo, acreditamos que teremos em 
mãos uma caixa-preta sempre em vias de ser exposta ou colocada em questão, seja nas descrições deste texto ou em sala de aula, quando a fabricação do jogo for assunto de interesse para os estudos da Psicologia Escolar (LATOUR, 2001a).

\section{DELEGAC̣̃̃O}

Às técnicas podemos delegar ações para a organização dos coletivos. Com elas definimos programas de ação e diversificamos o modo de expressá-los, socializando nossos valores e regras de convívio com entidades não humanas. Neste estudo, delegamos a um jogo a dupla função de produção de dados para esta pesquisa e a distribuição criativa de tarefas para a prática das habilidades do psicólogo escolar. Devemos ressaltar que esta última função deverá ser o ponto central de nosso trabalho. Afinal, procuramos investigar os modos de agir e pensar de um psicólogo escolar e como estes podem ser traduzidos na mecânica de um jogo para computador.

Se entendemos que a mediação é um trabalho presente em qualquer atividade de produção de conhecimento e que é no meio onde ocorrem os efeitos das trocas de propriedades entre as entidades em interação, nosso foco recai sobre a tentativa de compreender o modo como a realidade é mobilizada e traduzida na ação. No caso de um game educativo, a mobilização ocorre em seu planejamento, construção e uso, já que cada uma dessas etapas não prescinde das traduções que irão aliar diferentes programas de ação na consecução de objetivos lúdico-educativos.

No desenvolvimento de um jogo, procuramos mobilizar o tema da Psicologia Escolar em elementos que comungam com o domínio de uso e produção próprio dos videogames (TELES et al., 2011) na tentativa de deflagrar as mobilizações esperadas em ocasiões educacionais. Para tanto, colocamos à prova a problematização da Psicologia Escolar na construção de personagens e de uma narrativa, na distribuição programada de pontos, em ciclos de progressão para aprendizagem de habilidades, na escolha estratégica dos problemas apresentados em diferentes fases, no estilo de arte e projeto dos personagens etc. Em um arranjo sociotécnico como esse, a aprendizagem deverá ser, ao mesmo tempo, fruto de escolhas, desvios e de interesses partilhados. Designers, programadores, pesquisadores, software e estudantes marcam posições que produzem os efeitos didáticos que, como pesquisadores, perseguimos com disposição investigativa e de intervenção. 
A concepção do game como um dispositivo de aprendizagem e pesquisa não visa revelar disposições pré-determinadas ou avaliar a legitimidade das ações de seus usuários diante da categoria de fenômenos reunidos nos estudos da Psicologia Escolar. O jogo é portanto uma estrutura que nos permite falar desses fenômenos e estudos de outras formas. A Psicologia Escolar que nos interessa é aquela em ação, produzida e mediada entre humanos e não humanos. Por conseguinte, a diversidade das redes por onde circulam os games, a educação e a psicologia não são tomadas como unidades pré-existentes de análise ou objetos sobre os quais tecemos considerações. Com o método da TAR, não pesquisamos sobre mas em conjunto com aqueles que participam de nossos estudos, conforme recomendações inspiradas em uma política do conhecer, ou epistemologia política como veremos a seguir.

\section{EPISTEMOLOGIA POLÍTICA}

A noção de rede de Latour (1994a) nos ensina que em um mundo povoado por entidades humanas e não humanas, a prática da simetria não apenas garante a preservação da dignidade ontológica de todos os entes, mas evidencia, paradoxalmente, suas diferenças na produção dos fatos que protagonizam. No trabalho de mediação da atividade educativa, essa disposição simétrica nos permite entender o que é e o que pode ser colocado em movimento quando estabilidades formativas estiverem em pauta no programa de ação daqueles que são convocados a agir. Sob as contribuições das teorias da Autopoiese (MATURANA E VARELA, 1997) e da Enação (VARELA et al., 1991; Varela, 1997), a abordagem simétrica poderá contribuir para constituir uma experiência que escape da armadilha da pura representação e lhe devolva o direito à invenção, na fabricação dos próprios critérios de relação com o mundo.

Se a expressão e a produção das diferenças consistem na própria matéria que sustenta nosso argumento pela adoção da abordagem simétrica, resta-nos sistematizar as estratégias que pretendemos utilizar para garantirmos o respeito ontológico às entidades que associamos ao composto sociotécnico que denominamos jogo educativo. Seguindo as orientações de Latour (2007) e das autoras Vinciane Despret (2004) e Isabelle Stengers (2000), podemos pensar em uma epistemologia política que não só reconheça o caráter performático da produção de qualquer conhecimento mas que também procure fazer valer o princípio de simetria que defendemos como básico para o estudo das redes. 
A seguir, apresentamos cada conceito da epistemologia política defendida por Latour (2007; QUEIROZ E MELO, 2010; 2011) e como estes podem operar práticas específicas de conhecimento com o game que temos construído para a formação do psicólogo escolar.

\section{A) APRENDER É ARTICULAR-SE, AFETAR E DEIXAR-SE AFETAR PELAS PROPRIEDADES DE UM MUNDO NA PRÓPRIA REALIZAÇÃO DO QUE SIGNIFICA SER UM CORPO}

Segundo Latour (2007), somente uma concepção de conhecimento calcada no binarismo sujeito-objeto se interessaria em retirar do corpo todas as vicissitudes que o impedem de produzir afirmações exatas sobre o mundo. Em vez disso, o autor prefere aceitar a tese de que o corpo é a nossa interface comum, sem a qual qualquer experiência é impossível. Por ser um corpo em devir, o pesquisador se imbui de artefatos que lhe permitem descrever cada vez mais os fenômenos que interessam ao seu campo de estudo. Laboratórios, textos e eventos científicos, todos participam de um coletivo que contribui para a produção de corpos que investigam. O conhecimento, portanto, não se deflagra apenas porque o aprendiz direciona sua atenção a determinadas distinções do mundo. Diferente disso, essas próprias distinções são o produto das articulações que aprende a tecer. É na troca de propriedades com o mundo que o sujeito se hibridiza e oportuniza a emergência da novidade. Novas conexões geram novas sensibilidades que conferem ao corpo uma disposição dinâmica, capaz de torná-lo único, interessante e por isso apto a mobilizar redes mais extensas do que podia anteriormente.

Semelhantemente, acreditamos que um game para a formação do psicólogo escolar funcione como um artefato útil para nutrirmos controvérsias sobre um campo de estudos. Como um aliado às práticas de reflexão sobre os fenômenos do cotidiano de uma escola, um jogo poderá servir de território para explorações teóricopráticas incorporadas. Nesse sentido, jogar para conhecer é apenas uma das formas de deflagrar uma aprendizagem ativa, que leve em conta aqueles efeitos resultantes da mútua afetação entre jogo e jogador. As articulações possíveis são inúmeras. Podemos supor que, em sala de aula, limitações óbvias que cercam o uso didático de um jogo sobre um campo tão vasto como a Psicologia Escolar possam, paradoxalmente, instigar à construção de estratégias mais complexas de conhecimento, que conduzam a diferenciações interessantes e até então imprevistas no cenário inicial do software. Nessas ocasiões, a caixa-preta do jogo poderá ser aberta e suas condições de existência questionadas e articuladas a outros contextos e histórias, igualmente interessantes e oportunas para a produção de aprendizes. 


\section{B) O CONHECIMENTO DEVE SER INTERESSANTE}

Para interessar, a ocasião para a aprendizagem precisa provocar, fazer sentido, ir ao encontro daquilo que mobiliza os interesses do aprendiz. É por isso que as estratégias de ensino-aprendizagem mais férteis não são aquelas que tecem afirmações prontas sobre o que há no mundo, mas aquelas que permitem a criação de outros mundos, disponibilizando aberturas para o máximo possível de articulações. Além disso, despertar o interesse é uma forma de fazer jus ao princípio de simetria no processo educativo; constituindo um espaço de criação no qual aquilo que se ensina pode ser tomado também como um projeto alinhado às expectativas do outro.

Os games, por si sós, arrastam um emaranhado de redes nas quais circulam interesses diversos de quem joga em dispositivos móveis, em consoles, em redes sociais ou até mesmo de quem apenas ouviu a hipótese de que os jogos eletrônicos, de modo geral, são uma perda de tempo. Vale ressaltar que também são mídias complexas, pois abrangem, ao mesmo tempo, narrativas, animações, música e, no nosso caso específico, um evidente objetivo educacional. Ao aproximarmos essas redes do campo de problemas da Psicologia Escolar, inventamos mais um híbrido cujos efeitos ainda não conhecemos. Porém, montamos um cenário diante do qual alguém dificilmente permaneceria indiferente. Se formos bem-sucedidos em cooptar o interesse do outro, podemos esperar experiências articuladas de aprendizagem que comecem com a seguinte pergunta: é possível aprender Psicologia Escolar com um jogo de computador?

\section{C) O CONHECIMENTO ENVOLVE RISCOS}

Em qualquer atividade de pesquisa ou ensino orientada pelo princípio de simetria, deve-se abandonar a segurança da posição de comando, bem como as certezas acerca do conhecimento que está em jogo. No risco reside a possibilidade da reelaboração, da desmontagem do cenário para acomodar a participação mais legítima do outro. O próprio papel do professor poderá suspender sua hierarquia a favor da surpresa, do imprevisto que poderá transformá-lo em mais um entre tantos outros aprendizes. A aprendizagem depende de riscos. Por isso, precisamos abrir mão também das garantias teóricas e metodológicas para oportunizar a criação, o questionamento e o interesse.

Neste estudo, corremos riscos como pesquisadores interessados em performar ocasiões de aprendizagem sobre o papel do psicólogo escolar. Ao mesmo tempo, produzimos um software que concretiza os 
maiores riscos que poderíamos correr: apresentar um jogo capaz de articular-se com o campo de estudos da Psicologia Escolar. Como um produto final, o jogo ainda colocará em risco a performance do jogador que, para prosseguir em uma partida, precisa aceitar o fato de que suas escolhas consistem em estabilidades provisórias, em tensão constante com a mecânica do jogo, suas configurações e os movimentos erráticos das discussões travadas em sala de aula.

\section{D) IDENTIFICAR AS RECALCITRÂNCIAS ENTRE HUMANOS E NÃO HUMANOS}

Ao considerarmos que aprender/ensinar enseja um espaço de negociação, as recalcitrâncias devem ser identificadas para oportunizar o desenvolvimento de outras estratégias. Essa observação ainda denota o risco da ocorrência de seu oposto: a condescendência, a acomodação sem resistências ao programa de ensino que, em vez de produzir diferenças interessantes, apenas empobrece o trabalho de mediação. Por outro lado, em função das recalcitrâncias, os objetos de estudo interferem em nossos programas de ação, demonstrando as dissonâncias entre as questões que gostaríamos de investigar e as respostas possíveis.

Como um mediador não humano, o dispositivo do jogo deve ser preparado para deflagrar tais recalcitrâncias e não se limitar a reproduzir normas sobre como proceder em uma escola. Em interação com o jogador, portanto, o game deve fomentar a rebeldia questionadora, e não a mera aceitação do que está proposto. Nas ciências duras, esse conceito opera de modo ainda mais claro. Tomemos como exemplo o laboratório de química que explodirá caso o cientista não esteja interrogando suas entidades pesquisadas com as melhores perguntas. Além disso, acreditamos que recalcitrar é uma das ações possíveis diante de muitos jogos eletrônicos, nos quais as tarefas são projetadas para desafiar as capacidades do jogador em desenvolver novas habilidades. Trata-se da execução de mecanismos que agem diretamente no espaço que demarca a diferença entre o que o jogador consegue fazer e o que ele precisa aprender se quiser continuar jogando. Por esse motivo, um game tende a facilitar a identificação das recalcitrâncias, que poderão surgir quando o programa de ação do jogo não for mais capaz de manter o interesse do jogador pela aprendizagem.

\section{E) OFERECER OCASIÕES PARA DIFERIR}

Os dispositivos que utilizamos para investigar ou ensinar nunca são absolutos e não podem servir de barreira entre quem 
ensina e quem aprende. No cumprimento desta premissa, o professor pode demonstrar interesse e permitir que o aprendiz também se interesse com base em seus próprios recursos e objetivos, tomando suas manifestações como legítimas e não como interferências a serem eliminadas em privilégio do dispositivo ou do cronograma de estudo. A aprendizagem poderá então passar a ser organizada no encalço dos eventos que ocorrem em um encontro no qual, ao outro, sempre se concede o direito de diferir.

Aprender com um game poderá significar o abandono das posições rígidas em suspensão de quaisquer hierarquias. Nos referimos à oportunidade de tratar do conhecimento sobre a Psicologia Escolar como um convite ao brincar, mas nem por isso de modo menos relevante ou menos estratégico para nossos propósitos. Por conseguinte, a produção de diferenças poderá ser o resultado de um operar em conjunto com a performatividade de um dispositivo, sem os constrangimentos que orientam aprendizagens com base no que é certo ou errado. Em um espaço que prima pela ludicidade, diferir pode também ser o mesmo que ultrapassar o prescrito, recorrendo a estratégias novas e maximizando a mediação.

\section{F) DISTÂNCIA OU EMPATIA NÃO SÃO GARANTIAS DE APRENDIZAGEM}

Embora aprender ou ensinar seja diferir com o outro, nenhuma das partes deve deixar de lado seus próprios objetivos. A expressão dos sentimentos só é útil se não perdermos de vista seu papel como instrumento para oportunizar momentos em que o outro apresente suas próprias questões para o estudo. Portanto, não cabe escolher entre estar empático ou distante, mas ponderar sobre como transformar suas próprias disposições em recursos a favor da mediação. A distância que deve interessar é apenas aquela estabelecida entre o conjunto de ações iniciais e aquele posterior ao início da aprendizagem.

Em uma aprendizagem baseada em games, dificilmente qualquer um dos envolvidos permaneceria inerte diante de uma mídia que reúne música, narrativa e animação, combinadas para produzir uma experiência programada de determinado domínio do conhecimento. Discutir a Psicologia Escolar com as possibilidades desse tipo de interface poderá ser equivalente a acompanhar o desenvolvimento de uma história, com os altos e baixos de quem torce pelo sucesso do personagem principal. Podemos supor, a partir disso, que conduzir sessões de partidas com um game educativo é uma forma de se surpreender e de se entusiasmar com o outro. No entanto, emocionarse não deve confundir os interesses de quem ensina ou joga na medida 
em que um jogo cobra posicionamentos, exige reajustes constantes no foco e na atenção e registra os movimentos do jogador. Portanto, delegamos ao jogo parte da disposição necessária que poderá fazer do professor um facilitador atento e ao mesmo tempo envolvido.

\section{G) AS BOAS E MÁS GENERALIZAC̣̃̃ES}

Na proposta de um conhecimento produzido por proposições e não mais por afirmações sobre o mundo, as más generalizações seriam aquelas que efetuam cortes, suprimindo diferenças e elevando ao status de universal aquilo que foi encontrado apenas localmente. Em vez disso, as boas generalizações passam ao largo da redundância das afirmações e encontram sentido no âmbito das redes. As proposições bem-articuladas são aquelas que buscam conexões inéditas, na tentativa de implicar a existência de algumas entidades aos movimentos de muitas outras.

No que diz respeito ao campo da Psicologia Escolar, esperamos que um game educativo possibilite compreender o fenômeno "escola" também como uma rede. Diante de demandas explícitas de professores que exigem o diagnóstico do psicólogo, por exemplo, caberão generalizações que indiquem como determinadas demandas institucionais implicam outras entidades, além daquelas presentes nos discursos dos demandantes. Nesse ponto, destacamos o fato de que as articulações são fruto da inventividade presente nas atividades de qualquer tipo de ensino-aprendizagem. Aprender é inventar novas formas de articular e articular-se aos elementos do mundo, assim como aproximar dois domínios aparentemente distintos, como a Psicologia Escolar e os games.

\section{H) PERMITIR A EMERGÊNCIA DE UM MUNDO COMUM}

Eis o pilar que sustenta a proposição de uma epistemologia política: permitir a emergência de um mundo comum. Se entendemos que qualquer epistemologia é política, por princípio, resta-nos decidir não apenas a melhor forma de conhecer o mundo, mas quais posicionamentos são mais eficazes em permitir a manifestação do maior número possível de entidades que abrangem a extensão das redes das quais participamos. Sob essa noção, encontram-se todos os pontos discutidos acima. Um mundo comum só é possível se as bases para a produção do conhecimento não forem definidas de antemão sem a participação de todos os interessados. Poderíamos dar sentido à realização dessa proposta nos coletivos sociotécnicos, de modo geral, incluindo a ciência e a educação. 
Essas ideias iluminam questões centrais de nossa pesquisa. Entre elas, destacamos os contextos múltiplos de aprendizagem propiciados pelas tecnologias da informática em contraste com a educação formal que ainda parece preservar políticas de educação incompatíveis com tais mudanças. Consequentemente, enquanto as novas mídias encontram pouco ou nenhum acolhimento pelo ensino tradicional na organização de seus currículos, as possibilidades de um mundo comum são obstadas pelas práticas de purificação da modernidade, que, paradoxalmente, criam novos híbridos para lidar com as diferenças, tais como: imigrante $\mathrm{x}$ nativo digital, educador $\mathrm{x}$ educando, design instrucional x game design, sujeito x objeto.

Aprender, no entanto, requer o abandono dessas e tantas outras garantias para a inclusão do outro em um espaço pautado mais pelo compartilhamento de ideias do que pela transmissão de conceitos prontos. Um game, por conseguinte, poderá funcionar como um recurso para o exercício da improvisação. Um mapa que, em vez de indicar caminhos únicos, comporte espaços não preenchidos à espera do trabalho coautoral do outro para a construção de mais versões sobre a Psicologia Escolar.

\section{CONSIDERAÇÕES FINAIS}

Neste texto, apresentamos proposições teóricas que sustentam o desenvolvimento de um jogo educativo para a formação do psicólogo escolar. A proposta de uma epistemologia política para desenvolvimento e uso de um artefato lúdico com base na TAR nos surge como um subsídio teórico-prático que corrobora princípios defendidos pelas Teorias da Autopoiese e da Enação sobre a noção de cognição incorporada. Um ponto comum entre essas teorias reside na ideia de que a possibilidade de conhecer o mundo à nossa volta não prescinde do direito de reconstruí-lo: qualidade de uma posição simétrica e não meramente representativa. Diante disso, embora a relação com e entre os humanos não esteja em nosso primeiro plano de análise, a disposição ética no ensino e na pesquisa não são meros acessórios institucionais, mas fundamentos básicos para a garantia da expressão da diversidade no estudo dos fenômenos em rede.

Nesta proposta, educador e educando permanecem no mesmo patamar ontológico e em posições descentralizadas de autoria e interferência. Os desdobramentos pedagógicos, além de ampliarem o escopo de ação de alunos e professores, consistem na introdução de mais controvérsias em sala de aula, uma vez que o jogo eletrônico 
mobiliza programas de ação previstos no currículo institucional, na programação de um software, em nossos interesses de pesquisa e na temática da Psicologia Escolar.

Esperamos que o acolhimento de nosso jogo eletrônico oportunize o estabelecimento de outros programas de ação, seja na realização de proposições articuladas ou em crítica produtiva ao modo como a Psicologia Escolar é produzida, ensaiada e traduzida em sala de aula. Para tanto, nosso arranjo sociotécnico deverá ser preparado para ensejar recalcitrâncias, arriscar quaisquer suposições de eficiência de software e de nosso programa de pesquisa, além de dissolver dicotomias como sujeito-objeto, professor-aluno, real-fictício, real-construído.

\section{REFERÊNCIAS}

ABRAGAMES. (2004). Plano Diretor da Promoção da Indústria de Desenvolvimento de Jogos Eletrônicos no Brasil - Diretrizes Básicas; Comitê de Promoção da Indústria de Desenvolvimento de Jogos Eletrônicos no Brasil.

CALLON, M. (1987). Society in the making: the study of technology as a tool for sociological analysis. In: THOMAS, P. et al. (Org). The social construction of technological systems: new directions in the sociology and history of technology. Baskerville: MIT Press. p. 83-103.

CALLON, M.; LAW, J. (1997). After the individual in society: lessons in collectivity from science, technology and society. Canadian Journal of Sociology, Edmonton, v. 22, n. 2, p. 165-182.

CLARK, D. B. (2012). Prediction and Explanation as Design Mechanics in Conceptually Integrated Digital Games to Help Players Articulate the Tacit Understandings They Build through Game Play. In: STEINKUEHLER, C.; SQUIRE, K. D.; BARAB, S. (Orgs). Games, Learning, and Society: learning and meaning in the digital age, Cambridge University Press, p. 129-151.

CONSELHO FEDERAL DE PSICOLOGIA. (2000). Resolução no . 014/00, de 20 de dezembro de 2000. Institui o título profissional de Especialista em Psicologia e dispõe sobre normas e procedimentos para seu registro, Brasília.

COOPER, S.; KHATIB, F.; TREUILLE, A.; BARBERO, J.; LEE, J.; BEENEN, M.; LEAVER-FAY, A.; BAKER, D.; POPOVIĆ \& FOLDIT Players. (2010). Predicting protein structures with a multiplayer online game. Nature 466, p. 756-760.

DESPRET, V. (2004). Our Emotional Makeup: Ethnopsychology and Selfhood. Other Press, LLC. ENTERTAINMENT SOFTWARE ASSOCIATION (ESA) (2009). Essential facts about the computer and videogame industry. Washington, DC: ESA.

GARTNER, I. (2011). Report Market Trends: Gaming Ecosystem, 2011. Disponível em: <http://www.gartner.com/it/page.jsp?id=1737414>. Acesso em: 28 ago. 2012.

GEE, J. (2008a). A sociocultural perspective on opportunity to learn. In: MOSS, P; PULLIN, D; GEE, J, HAERTEL, E. \& YOUNG, L. (Orgs). Assessment, equity and opportunity to learn. Cambridge, New York, Melbourne, Madrid, Cape Town, Singapore, Sao Paulo, and Delhi: Cambridge University Press, pp. 76-108.

GEE, J. P. (2002). Learning in semiotic domains: A social and situated account. National Reading Conference. Yearbook, 51, 23-32. 
GEE, J. P. (2003). What videogames have to teach us about learning and literacy. New York: Palgrave Macmillan.

GEE, J. P. (2005). Game-like learning: An example of situated learning and implications for opportunity to learn. In: MOSS, P; PULLIN, D; GEE, J, HAERTEL, E. \& YOUNG, L. (Orgs). Assessment and opportunity to learn: New voices, new views. Cambridge: Cambridge University Press.

GEE, J. P. (2008b). Learning and Games. In: SALEN, K. (Org.). The Ecology of Games: Connecting Youth, Games, and Learning. The John D. and Catherine T. MacArthur Foundation Series on Digital Media and Learning. Cambridge, MA: The MIT Press, pp. 21-40.

GEE, J. P.; HAYES, E. (2012). Nurturing Affinity Spaces and Game-Based Learning. In: STEINKUEHLER, C.; SQUIRE, K. D.; BARAB, S. (Orgs). Games, Learning, and Society: learning and meaning in the digital age, Cambridge University Press, pp. 129-151.

HOFFMAN, H. G., PATTERSON, D. R., \& CARROUGHER, G. J. (2000). Use of virtual reality for adjunctive treatment of adult burn pain during physical therapy: A controlled study. The Clinical Journal of Pain, 16(3), 244-250.

JENKINS, H. (2006). Confronting the Challenges of Participatory Culture. Chicago, IL, MacArthur Foundation.

KASTRUP, V. (1999/2007). A invenção de si e do mundo: uma introdução do tempo e do coletivo no estudo da cognição. Editora Autêntica: Belo Horizonte.

KASTRUP, V. Enatuar. (2012). In FONSECA, T. M; NASCIMENTO, M. L.; MARASCHIN,

C. (Orgs). Pesquisar na diferença: um abededário. Porto Alegre: Sulina.

KATO, P. M. (2010). Video games in health care: Closing the gap. Review of General Psychology, 14(2), 113.

LATOUR, B. (1988). The pasteurization of France. Cambridge: Harvard University Press, 1988. LATOUR, B. (1991). Technology is society made durable. In: LAW, J. (Org.). A Sociology of Monsters. Essays on Power, Technology and Domination. London, Routledge, pp.103-131.

LATOUR, B. (1994a). Jamais fomos modernos (Trad. Carlos Irineu da Costa). RJ, Editora 34.

LATOUR, B. (1994b). Pragmatogonias. Um relato mítico sobre como humanos e não humanos trocam propriedades. Traduzido do original Pragmatogonies. A mytical account of how humans and non-humans swap properties. In: ASHMORE, M. (Org.) Special Issue of Behavioral Sciences, 37(.6), p. 791-808.

LATOUR, B. (1996). Do humano nas técnicas. In: SCHEPS, R. (Org.). O Império das técnicas (p. 155-166). Campinas: Papirus.

LATOUR, B. (2000a). Ciência em ação. Como seguir cientistas e engenheiros sociedade afora. São Paulo: Editora Unesp.

LATOUR, B. (2001a). A esperança de Pandora: ensaios sobre a realidade dos estudos científicos. Bauru, SP: Edusc.

LATOUR, B. (2001b). Gabriel Tarde and the End of the Social. In: JOYCE, P. (Org.). The Social and its Problems (pp. 117-132). Londres: Routledge.

LATOUR, B. (2007). Como falar do corpo? A dimensão normativa dos estudos sobre a ciência. In: J. NUNES, A. \& ROQUE, R. (Orgs.). Objetos impuros. Experiências em estudos sociais da ciência. Porto: Edições Afrontamento, p. 39-61.

LATOUR, B., (2005). Reassembling the Social, Oxford, Clarendon. 
LATOUR, B; Woolgar, S. (1997). A vida de laboratório: a produção de fatos científicos. Rio de Janeiro: Relume Dumará.

LATOUR. B. (2000b). Factures/fractures. De la notion de réseaux à celle d'attachment. In Micoud, A., et Peroni, M. Ce qui nous relie. La Tour d'Aigues, Editions de l'Aube, pp. 189-208.

LAW, J. (1987). Technology, closure and heterogeneous engineering: the case of the Portuguese expansion. In: BIJKER, W.; HUGHES, T. P.; PINCH, T. (Orgs). The social construction of technological systems: new directions in the sociology and history of technology. Baskerville: MIT Press. p. 111-134.

LAW, J. (2002). Aircraft stories: decentering the object in technoscience. Durham: Duke University Press.

LAW, J.; CALLON, M. (1988). Engineering and sociology in a military aircraft project: a network analysis of technical change. Social Problems, Berkeley, v.35, n.3, p. 284-97.

LAW, J; CALLON, M. (1992). The life and death of an aircraft: a network analysis of technical change. In: BIJKER, W. E.; LAW, J. (Orgs.). Shaping technology / Building society: studies in sociotechnical change. Cambridge: MIT Press. p. 21-52.

MARASCHIN, C.; AXT, M. (2005). Acoplamento Tecnológico e Cognição. In: VIGNERON, J.; OLIVEIRA, V.B. (Orgs.). Sala de Aula e Tecnologias. São Bernardo do Campo: Universidade Metodista de São Paulo, 39-51.

MATURANA, H., Varela, F. (1995). A árvore do conbecimento. Campinas: Editorial Psy.

MATURANA, H.; Varela, F. (1997). De máquinas e seres vivos: autopoiese - a organização do vivo. 3. ed. Porto Alegre: Artes Médicas.

MICHAEL, D.; CHEN, S. (2006). Serious games: Games that educate, train, and inform. Thomson, Boston, MA.

MORAES, M. (1998). Por uma estética da cognição: A propósito da cognição em Latour Stengers. Revista Informare. Rio de Janeiro, v.4, n.1, p. 49-56.

MORAES, M. O. (1997). Estudo das Técnicas na Perspectiva das Redes de Atores [Versão eletrônica]. Revista do Departamento de Psicologia da UFF, Niterói, v. 9, n. 2 e 3, 60-67.

QUEIROZ E MELO, M. F. A. (2010). Algumas aprendizagens construídas durante a brincadeira de pipa: o que está em jogo. Educação em Revista, 26(2), 89-116.

QUEIROZ E MELO, M. F. A. (2011). Discutindo a aprendizagem sob a perspectiva da teoria ator-rede. Educar em Revista, Curitiba, Brasil, n. 39, jan./abr, pp. 177-190.

SATWICZ, T.; Stevens, R. (2007). Tools of play: coordinating games, characters, and actions while learning to play video games. In: Proceedings of the 8th International Conference on Computer Supported Collaborative Learning (New Brunswick, New Jersey, USA, July 16 - 21, 2007). CHINN, C. A; ERKENS, G.; \& PUNTAMBEKAR, S. (Orgs). Cscl Conference On Computer Supported Collaborative Learning. International Society of the Learning Sciences, 633-642.

SATWICZ, T.; STEVENS, R. (2008). Playing with Representations: How Do Kids make Use of Quantitative Representations in Video Games? International Journal of Computers for Mathematical Learning, 13, p. 179-206.

SHAFFER, D. W. (2012). In: STEINKUEHLER, C.; SQUIRE, K. D.; BARAB, S.. (Orgs.). Games, Learning, and Society: learning and meaning in the digital age, Cambridge University Press, p. 403-431. 
SHAFFER, D. W., GEE, J. P. (2005). Before every child is left behind: How epistemic games can solve the coming crisis in education (WCER Working Paper No. 2005-7). Madison: University of Wisconsin Madison, Wisconsin Center for Education Research.

SHAFFER, D. W.; GEE, J. P. (2006). How computer games help children learn. Palgrave Macmillan.

SQUIRE, K. D. Jan, M. (2007). Mad City Mystery: Developing Scientific Argumentation Skills with a Place-based Augmented Reality Game on Handheld Computers. Journal of Science Education and Technology, v. 16, N. 1, February.

STEINKUEHLER, C. A. (2006a). Why game (culture) studies now? Games and Culture, 1(1): 97-102.

STEINKUEHLER, C. A. (2006b). The Mangle of play. Games and Culture, 1(3): 1-14.

STEINKUEHLER, C.; Squire, K. D.; \& Barab, S. (2012). Games, Learning, and Society: learning and meaning in the digital age, Cambridge University Press.

STENGERS, I. (2000). Another look: Relearning to laugh. Hypatia, 15(4), 41-54.

STEVENS, R.; Satwicz, T.; \& McCarthy, L. (2008). In-Game, In-Room, In-World: Reconnecting Video Game Play to the Rest of Kids' Lives. In: SALEN, K. (Org.). The Ecology of Games: Connecting Youth, Games, and Learning. The John D. and Catherine T. MacArthur Foundation Series on Digital Media and Learning. Cambridge, MA: The MIT Press, p. 41-66.

TELES, F. (2011). A cooperação na performance do lúdico: investigando um dilema social com um jogo de simulação computacional, Dissertação de Mestrado, Universidade Federal de São João del-Rei, São João del-Rei.

TELES, F. ; BENIGNO, G. F. ; GUANAIS, V. A. ; SANTOS, L. M. M. ; MARASCHIN, C. ; \& SILVA, D. L. (2011). Um jogo educativo para formação do Psicólogo Escolar: elaboração de um dispositivo lúdico. RENOTE. Revista Novas Tecnologias na Educação, v. 9, p. 1-1.

TELES, F.; QUEIROZ E MELO, M. F. A.; \& NEPOMUCENO, E. G. (2012). Reflexões sobre a utilização de um videogame multiplayer para investigar o fenômeno da cooperação em psicologia social. Pesquisas e Práticas Psicossociais, v. 6, p. 287-297.

TSALLIS, A. C.; FERREIRA, A. A. L.; MORAES, M. O.; \& ARENDT, R. J. (2006). O que nós psicólogos podemos aprender com a Teoria Ator-Rede? Interações, 12(22), p. 57-86.

VARELA, F. J.; THOMPSON, E.; \& ROSCH, E. (1991). The embodied mind: Cognitive science and human experience. Cambridge, MA: MIT Press.

VARELA, F. (1997). Conhecer as ciências cognitivas, tendências e perspectivas. Lisboa: Instituto Piaget.

\section{NOTAS}

${ }^{1}$ Verbo derivado de enação conforme sugestão de Kastrup (2012).

Recebido: 20/07/2013

Aprovado: 01/11/2014 
Contato:

Universidade Federal do Rio Grande do Sul

Programa de Pós-Graduação em Informática na Educação Av. Paulo Gama, 110 - prédio 12105 - $3^{\circ}$ andar sala 332

Porto Alegre |RS |Brasil

CEP 90.040-060 
